\title{
Contratos Eletrônicos
}

\section{Luís Humberto Nunes Quezado}





\section{Contratos Eletrônicos}

co Internet - Nascimento, Desenvolvimento e Atualidade

\subsection{INTRODUÇão}

Nesse capítulo inicial, vamos tecer algumas questões interessantes sobre esse novo meio de comunicação conhecido como Internet. De um ousado projeto militar norte-americano, tornou-se um dos meios de comunicação mais usados atualmente.

Em virtude disso, como o Direito deve sempre acompanhar a eterna evolução da sociedade, a Ciência Jurídica tem que estar pronta para reger as novas implicações sociais decorrentes desse novo fenômeno, e em virtude disso, estão sendo constantemente criadas novas leis ou modificadas as já existentes, no intuito do Direito estar sempre acompanhando as exigências da sociedade.

Ora, a Internet veio, também, como uma nova forma de se manter relações sociais, entre elas, os contratos.

As antigas leis civis que dispunham sobre contratos, por motivos de ordem tecnológica, ainda não albergavam os chamados contratos eletrônicos. No entanto, faz-se necessária a criação de leis acerca desse tipo de contrato, e, enquanto as mesmas não são criadas, deve-se dar uma interpretação analógica dos novos contratos eletrônicos acerca de sua formação, pagamento e outros aspectos.

Portanto, a finalidade do presente trabalho é correlacionar as já existentes leis civis ao recente fenômeno da “informatização dos contratos”. 


\subsection{Como Nasceu e SE DESENVOLVEu a INTERNET}

Em 1960, os soviéticos haviam criado uma arquitetura eletrônica conhecida como ARPANET ${ }^{1}$. Então os norte-americanos, temendo a expansão e o crescimento do comunismo e influenciados por uma doutrina, conhecida como mcarthismo ${ }^{2}$, em 1969, os militares daquela nação criaram um projeto que se preocupava em montar uma estrutura de comunicação independente, que superasse o potencial de comunicação soviético, visto que a Guerra Fria estava na sua plenitude. Era um sistema que funcionaria mesmo que houvesse um ataque nuclear, não havendo possibilidade de ruptura na transmissão de dados.

Nesse tempo, o “embrião” da Internet cresceu espontaneamente, acabou por se espalhar (e se desenvolver) pelas Universidades e Centros de Pesquisa, ficando o acesso restrito somente a esses órgãos, por enquanto. Somente nos anos 80, quando os Computadores Pessoais se tornaram acessíveis à população, é que a Internet passou a ser utilizada pelo cidadão.

No início da década de 90, o cientista britânico Tim Bernes-Lee aperfeiçoou o sistema de comunicação e criou, por meio do Protocolo de Comunicações IP (Internet Protocol), uma linguagem universal até para computadores com tecnologia diferentes, a linguagem WWW (World Wide Web), ou “Teia Global”.

Então, à medida que as comunicações foram ficando mais e mais modernas e interligadas em todo o mundo, a Internet vem se tornando, nessa mesma proporção, cada dia mais fácil de usar, e com cada vez mais recursos disponíveis a quem dela se utiliza, como o $e$-mail ${ }^{3}$.

Já no Brasil, a Internet começou a ser utilizada, mesmo que muito parcamente, em 1995, sendo que o Comércio Eletrônico foi começar a ser utilizado apenas em 1998.

\footnotetext{
${ }^{1}$ ARPANET, de Advanced Research Projects Agency Net, em português: Rede da Agência de Projetos de Pesquisas Avançado.

${ }^{2}$ Mcarthismo é uma doutrina política idealizada na década de 40 - 50 pelo Senador americano McCarthy, que consistia numa verdadeira neurose anticomunista, baseada em calúnia e difamação dos ideais de Marx e Engels.

${ }^{3}$ E-mail, de eletronic mail, é uma versão eletrônica do correio comum. Uma pessoa, em um computador, em qualquer lugar do mundo pode enviar mensagens para qualquer outra pessoa em outro computador. É usado em larga escala atualmente.
} 


\subsection{QuestõEs Atuais}

Como a Internet já é uma realidade nos dias de hoje, nota-se, a partir desse fato que, além da mesma ser um agente de transformação da tecnologia, da economia e, sobretudo, da sociedade, ela é o instrumento pelo qual são produzidos alguns fenômenos sócio-jurídicos, tais como o E-Commerce (Comércio Eletrônico).

No entanto, como ela é ainda um fenômeno muito recente, é necessário que tenha um nível de segurança razoável, para que seja um meio viável de se manter relações comerciais.

\subsubsection{Comércio Eletrônico (E-Commerce)}

O Comércio eletrônico, ou E-Commerce são todas as formas de transação relativas a atividades comerciais, porém, todas feitas via transmissão e recepção de dados, característica única da Internet.

Através do E-Commerce é possível que uma pessoa, usando um computador em uma localidade qualquer do mundo, possa comprar qualquer coisa em uma outra localidade, por meio de uma conexão à Internet.

Existem dois tipos básicos de E-Commerce, o Business-to-Business (B2B), que é aquela relação comercial eletrônica que diz respeito à contratos celebrados entre partes que exercem profissionalmente uma dada atividade, como entre parceiros de negócio, o outro é o Businessto-Consumer (B2C), usado menos que o primeiro, em virtude das questões de Segurança (tratada no próximo tópico), é aquela relação comercial entre fornecedor e consumidor final, que adquire um produto ou serviço.

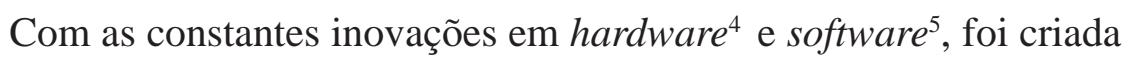
uma grande novidade no conceito de Comércio Eletrônico, que são as “lojas virtuais”, onde o consumidor escolhe, no próprio site da loja, o que quer comprar, fornece o número do cartão de crédito ou imprime um boleto para pagamento em banco, e pronto, a compra está feita, como numa loja comum.

${ }^{4}$ Partes físicas do Computador, como Monitor, teclado e mouse.

${ }^{5}$ Programas de Computador, como o Microsoft Windows, o Linux. 
A grande qualidade desse novo modo de compra está no fato de, apesar de estar sendo comprado via Internet, esse modo possibilita uma transação instantânea, ou seja, no momento em que se está lá, no site da loja, pode-se considerar realmente se fazendo uma compra. Não precisa haver uma confirmação, nem nada do tipo para efetuar a transação.

\subsubsection{Segurança}

Ainda hoje, a questão da Segurança e da Privacidade das Relações Contratuais feitas via Internet é o que ainda dificulta o uso confiável do comércio eletrônico.

Para que o Comércio Eletrônico o os Contratos Eletrônicos se tornem viáveis, se fazem necessárias duas coisas: primeiramente, necessita-se a aplicação de tecnologias para aumentar a Segurança na Transmissão e Recepção de Dados via Internet, para coibir a ação dos "crimes de informática” cometidos por pessoas especializadas em invadir computadores e burlar sistemas criptográficos, conhecidas como crackers $^{6}$, ou identificar, com uma grande margem de certeza, as partes contratantes. Atualmente, é usado o conceito de "Assinatura Digital”, que em nada se assemelha com o conceito de assinatura que conhecemos, ela é uma série de números, letras e símbolos, que somente pode ser acessada pelo seu portador. Essas Assinaturas Digitais são protegidas do acesso de outros por conta de um sistema de segurança conhecido como criptografia ${ }^{7}$.

Em segundo lugar, faz-se necessária a “atualização legislativa” do Brasil, no intuito de albergar as novas formas contratuais, em especial aquelas que são feitas via e-mail ou sites. O Brasil ainda está dando poucos passos no caminho de criar toda uma legislação sobre Comércio Eletrônico. Atualmente, conta-se com poucos Decretos ou Resoluções. Nesse sentido, a legislação Internacional já está acompanhando mais veementemente esta nova forma de Contratar. A Comunidade Européia, por exemplo, já conta com a Diretiva 1999/93/CE , que entre outras coisas, contém definições do que seja, para a Comunidade Européia, uma

\footnotetext{
${ }^{6}$ Essa palavra vem do Inglês crack, que significa quebrar, o cracker é aquela pessoa com um grande conhecimento técnico e utiliza tal conhecimento para praticar crimes de informática. É diferente do hacker, que é um pesquisador do ramo da Informática, um hacker não obrigatoriamente pratica crimes, ao contrário do que se pensa.

${ }^{7}$ Criptografia é a técnica de escrever em cifra ou em código. Foi muito utilizada em tempos de Guerra, mudando de forma drástica o rumo dos fatos.
} 
Assinatura Eletrônica (no art. $2^{\circ}$, 1), um Certificado Eletrônico (no art. $2^{\circ}$, 9), além de falar dos efeitos legais das Assinaturas Eletrônicas (art. $5^{\circ}$ ), e finaliza explicando como será feita a Aplicação dessa Diretiva (art. 13º).

\section{co Contratos Eletrônicos}

A partir de agora, o objetivo do trabalho será situar as novas relações contratuais, quais sejam, os Contratos Eletrônicos, dentro do universo dos contratos comuns, situados tanto na Parte Geral, como na Parte especial do Novo Código Civil.

\subsection{Definição de Contrato Eletrônico}

A definição do que chamamos de Contratos Eletrônicos ainda não é certa, visto que poucas legislações, seja de âmbito nacional ou internacional, não se preocuparam em tecer definições, deixando esse trabalho para a doutrina.

Portanto, existem inúmeras definições: Luis Wielewicki os define como “Todas as espécies de signos eletrônicos transmitidos pela Internet que permitem a determinação de deveres e obrigações jurídicas” ${ }^{\text {. }}$

Michelle Toshiko Terada, por sua vez, como "O encontro de uma oferta de bens ou serviços que se exprime de modo audiovisual através de uma rede internacional de telecomunicações e de uma aceitação suscetível de manifestar-se por meio da interatividade" 9 .

Sendo assim, nota-se que o Contrato Eletrônico é, bem como o Contrato comum, um tipo mais específico de Negócio Jurídico, contudo, para qualquer ato pertinente ao Contrato Eletrônico, desde a sua formação, faz-se necessário o uso da Internet.

\subsection{REQUISITOS ESSENCIAIS}

Como já sabemos, o contrato pode ser definido como uma modalidade de Negócio Jurídico, de natureza unilateral ou bilateral, ou seja, depende, para sua formação, de uma convergência (encontro) das vontades de ambas as partes, criando assim, uma norma jurídica individual reguladora de interesses privados.

${ }^{8}$ WIELEWICKI, Luis, Contratos e Internet - Contornos de uma breve Análise, Apud, Comércio Eletrônico, Org. JUNIOR, Ronaldo Lemos da Silva e WAISBERG, Ivo. São Paulo: RT, 2001.

9 TAREDA, Michelle Toshiko, contratos eletrônicos e suas implicações na ordem jurídica, Apud, Novas fronteiras do Direito na Informática e Telemática, Coord. BAPTISTA, Luiz Olavo. São Paulo: Saraiva, 2001. 
A noção de Negócio Jurídico cabe perfeitamente ao Contrato Eletrônico, visto que ambos necessitam dos mesmo requisitos.

Requisito objetivo é aquele que diz respeito ao objeto do Contrato, ou seja, ele (o objeto) deve ser lícito, possível, determinado ou determinável (art.104, II - NCC). Dizer que o objeto deve ser lícito significa que ele deve ser permitido pela lei e não ser contra a moral, aos princípios da ordem pública e aos bons costumes; possível significa que ele deve ter uma possibilidade de ser economicamente apreciável, além de ser tangível, ou seja, ter existência; determinado significa que ele deve ser fixado como certo, determinado de uma forma que não cause erros; determinável, é que a determinação deve ser, ao menos, em potência. Então, o objeto do Contrato Eletrônico é, na maioria das vezes, objeto semelhante aos mesmos dos contratos comuns, a única diferença é no modo de contratação, ou meio de entrega.

Requisito subjetivo é aquele que diz respeito às partes contratantes, que exige a existência de duas ou mais pessoas, que, via de regra, devem ser capazes (art. 104, I-NCC), ou devem ser, pelo menos, representadas ou assistidas por capazes, e também o consentimento de ambas, que seja livre de vícios ${ }^{10}$, para garantir da perfeita convergência volitiva. Esse requisito é perfeitamente cabível ao Contrato Eletrônico, haja vista que, por trás do computador, ou da "assinatura eletrônica” existe uma pessoa real que, possuindo uma capacidade genérica para contratar, pode contratar com quem desejar.

A questão polêmica é aquela concernente ao Requisito Formal, qual seja, aquele que diz respeito à forma do Contrato, que deve, segundo a lei, ser prevista ou não defesa em lei (art. 104, III - NCC). Entretanto, aqui também não existem empecilhos quanto à sua formação, visto que não existe nenhuma lei que o vede expressamente, sendo portanto, válido, no tocante à efeitos. Atualmente não existe o rigor de forma, sendo esta obrigatória apenas nos casos expressos em lei.

${ }^{10}$ Vício, num Negócio Jurídico, e consequentemente, num Contrato, é tudo capaz de impedir a manifestação idônea da vontade de alguma parte contratante, de forma tal que a vontade que foi expressada não corresponde ao desejo real do agente, esses vícios tornam o negócio jurídico nulo ou anulável.

Existem dois tipos de vícios, os Vícios de Vontade (Erro, Dolo, Coação, Estado de Perigo e Lesão), onde a vontade idônea do agente está sendo afetada por algo ou alguém, contra a sua vontade. E existem também os Vícios Sociais (Simulação e Fraude contra Credores), que são os vícios que tem o intuito de enganar terceiros, a vontade do contratante é real, no entanto, fere de sobremaneira o Princípio da boa-fé Contratual, já que é dirigida para prejudicar alguém. 


\subsection{Formação dos Contratos Eletrônicos}

Após a análise dos requisitos de validade e existência, a formação dos Contratos Eletrônicos será analisada frente às fases de formação dos contratos em geral.

Como já foi visto, para haver um contrato, de uma forma geral, é necessário somente a união de duas ou mais declarações de vontades concordantes (Convergência de Vontades), que gera uma "norma convencional”.

Sabe-se, que, antes da fase Pré-Contratual existe a fase das “Tratativas”, que consiste na negociação preliminar de cláusulas e outros detalhes do contrato, nessa fase, nada é obrigatório visto que não existe ainda, o vínculo jurídico, e sem esse último, não há a força vinculante dos contratos, e o mesmo se aplica aos Contratos Eletrônicos.

Passada a fase das Tratativas, chega-se à fase da proposta, ou seja, quando o policitante faz a oferta ao oblato. A proposta pode ser considerada como o marco inicial do contrato, devendo essa para figurar como proposta efetiva, ser séria, concisa e inequívoca. Dependendo do caso, essa oferta já pode ser obrigatória, com certas exceções, expressas no Código (arts. 427 e 428 - NCC). Essas exceções dizem respeito a se o contrato considerar-se-á celebrado entre presentes (inter praesentes), ou seja, estabelecido com a presença de ambas as partes, ou se é celebrado entre ausentes (inter absentes), que são aqueles em que as partes não se encontram "frente a frente", como no caso de contratos por carta ou telegrama, por exemplo.

Finalmente, fechando o ciclo de formação de um Contrato eletrônico, existe a fase da aceitação, que se inicia na oferta e termina com o fenômeno do encontro de vontades, manifestado pela aceitação, pela outra parte, dos termos propostos. È um ato essencial para a existência do contrato, visto que vincula as partes ao mesmo.

É sabido que, atualmente existem softwares de comunicação instantânea, tais como o MSN Messenger, ICQ, IRC, nesses casos, como ambas as partes estão conversando de forma instantânea, pode-se considerar como presentes, tanto para a proposta, quanto para a aceitação, visto que não há um intermediário que interfira na conversação ou um grande lapso temporal que descaraterize a instantaneidade. Ou seja, equipararia-se a contratar pelo telefone, apesar da distância entre ambas as partes. 
A contrario sensu, sobre o caso das propostas feitas pela Internet, geralmente através de home-pages ou mala direta em e-mail, já nesses casos, as partes se consideram ausentes, pois há um considerável lapso temporal entre a emissão da proposta e a recepção da mesma, e também existe um intermediário, que seria o provedor de e-mail. Nesses contratos, a oferta também deve atender aos requisitos de formalidade necessários para que a oferta se torne obrigatória ao policitante, ou seja, deve ser, na medida do possível ao meio eletrônico de comunicação, uma proposta efetiva, que seja própria da formação dos contratos.

\subsection{Uma ObServação Importante: TeOria da Expedição}

Vimos que nos Contratos Eletrônicos via e-mail, o contrato é feito entre ausentes, haja vista não haver contato direto entre os contratantes, e, como foi dito, existe um considerável lapso de tempo e um intermediário no caso. Sobre isso, a lei brasileira adotou a chamada Teoria da Expedição, que é uma das divisões de uma Teoria sobre o aperfeiçoamento dos contratos chamada de Teoria da Agnição, que diz que o contrato tem por aperfeiçoamento o momento em que o policitante conhece a aceitação por parte do oblato, possui duas modalidades: expedição e recepção.

A Teoria de Expedição diz que a aceitação entre ausentes se dará no momento da expedição da mesma por parte do oblato (art. 434, caput - NCC). No entanto, se o contrato for feito por meios onde exista a comunicação instantânea, será aplicada as normas concernentes aos contratos feitos entre presentes.

Quanto a retratação ${ }^{11}$, a regra também é a mesma. Segundo a lei, a retratação deve chegar ao mesmo tempo ou antes da aceitação formal, então, se a aceitação for dada, por exemplo, via e-mail, mesmo que a transmissão da mensagem seja praticamente instantânea, existe um período em que o e-mail fica no servidor (Ex.: Nos computadores da Yahoo, do Hotmail, ou de outro provedor), antes de ser descarregado ${ }^{12}$ para o computador do titular da conta de e-mail (que recebe a aceitação), quando este visita a página do provedor. Ou seja, se for possível o oblato enviar a aceitação e, pouco tempo depois, a retratação, quando o

${ }^{11}$ A retratação acontece quando o oblato desiste da aceitação.

${ }^{12}$ Quando o documento constante na mensagem de e-mail é copiado, via Internet, do provedor até o computador do usuário, após a apresentação do login e senha do e-mail. 
policitante for acessar sua conta de e-mail, verá as duas mensagens na “Caixa de Entrada” ainda não lidas. Pensa-se assim para que a parte que envia o $e$-mail não fique sujeita à freqüência pela qual a outra parte acessa a Internet para checar o seu.

Portanto considera-se recebido o e-mail (e, consequentemente, a aceitação ou a retratação) quando este é descarregado no computador de quem acessa o provedor, segundo boa parte da doutrina.

\subsection{Lugar de Formação dos Contratos Eletrônicos}

A determinação do lugar de Formação é de suma importância para todo o direito, no caso de não haver um foro de eleição no próprio contrato, também é muito importante no âmbito do Direito Internacional, visto que se trata de um fator determinante da legislação que irá reger os efeitos do mesmo.

"Reputar-se-á celebrado o contrato no lugar em que foi proposto" (art. 435 - NCC). Isso significa que será considerado celebrado o contrato no lugar onde foi feita a proposta. Essa disposição é válida para as relações de Direito Interno, visto que é disposta no Novo Código Civil. Se aplicaria, por exemplo, no caso de uma pessoa que compre algo via Internet em uma "loja virtual” de um estabelecimento que funcione no mesmo país.

Entretanto, para as relações contratuais no âmbito do Direito Internacional Público a Lei de Introdução ao Código Civil assim dispõe no seu $\S 2^{\circ}$ do art. 9": "A obrigação resultante do contrato reputa-se constituída no lugar em que residir o proponente”. Caberia no caso de alguém que compre, via Internet, em algum estabelecimento que não funcione em seu país, desde que não haja nenhum Tratado Internacional ou Acordo de Cooperação que digam respeito à contratos no âmbito do Direito Internacional.

Existe uma corrente minoritária, que diz que seria impossível definir com exatidão o lugar de formação dos Contratos Eletrônicos, alegando o fato de a Internet não ter um lugar definido, ser espalhada por todo o mundo. Entretanto, esse argumento pode rapidamente ser refutado, tendo em vista que a Internet é uma rede em que computadores estão nela conectados, e cada computador desse está situado em um país, sujeitando-se portanto à lei deste. 


\subsection{Notas Sobre o CDC e os Contratos Eletrônicos}

Uma boa parte, senão a maioria, dos Contratos Eletrônicos, são manifestações de Relações de Consumo, em virtude disso, o presente trabalho não seria completo se não tratasse também a relação dessas Novas Formas Contratuais com o Código de Defesa e Proteção do Consumidor (Lei ${ }^{\circ}$ 8.078/90).

Um dos princípios basilares da Lei do Consumidor é o Princípio da Transparência, que diz que o fornecedor deve ser, como sugere o nome, transparente em todo o contrato, desde a negociação até o adimplemento do mesmo, fornecendo, de uma forma clara e inequívoca todo o conteúdo do contrato para o Consumidor, no intuito de evitar o erro ou ignorância, por meio da parte protegida pelo diploma legal.

Esse princípio está explicitado em boa parte do CDC, entretanto, figura expressamente, como direito do Consumidor, no inciso III do seu art. $6^{\circ}$ : "São direitos básicos do consumidor: (...) III-a informação adequada e clara sobre os diferentes produtos e serviços, com especificação correta de quantidade, características, composição, qualidade e preço, bem como sobre os riscos que apresentem”.

Um outro dispositivo do CDC que regularia os Contratos Eletrônicos, principalmente aqueles que são efetuados por intermédio das "lojas virtuais”. Esse dispositivo seria o art. 49-CDC:

"O consumidor pode desistir do contrato, no prazo de 7 dias a contar de sua assinatura ou do ato do recebimento do produto ou serviço, sempre que a contratação de fornecimento de produtos ou serviços ocorrer fora do estabelecimento comercial, especialmente por telefone ou à domicílio”.

O artigo supra citado fala do arrependimento de que o consumidor tem direito, no caso do contrato ser firmado fora do estabelecimento comercial. Há alguns anos, só podia-se cogitar esse tipo de contratação se fosse via telefone ou à domicílio (Ex.: Revendedoras da “AVON”), no entanto, atualmente, esse entendimento aplica-se perfeitamente aos contratos firmado via Internet, haja vista que, do mesmo modo, o consumidor não tem um contato prévio com o produto. 


\section{\ Força Probatória dos Contratos Eletrônicos}

Não é o objetivo deste trabalho versar sobre o tema da Validade Jurídica dos Documentos Eletrônicos, no entanto, faz-se necessário tecer alguns comentários sobre o assunto, dada a sua pertinência com o tema sobre o qual o presente trabalho versa.

Inicialmente, os documentos eletrônicos já estariam albergados como meios de prova pelo Código de Processo Civil no seu artigo 332, já que esse artigo dizque:

“Todos os meios legais, bem como os moralmente legítimos, ainda que não especificados neste Código, são hábeis para provar a verdade dos fatos, em que se funda a ação ou a defesa".

Fortalecendo esse entendimento, o Código de Processo Civil versa, no seu art. 368: "As declarações constantes do documento particular, escrito e assinado, presumem-se verdadeiras, com relação ao signatário”.

Para um documento eletrônico equiparar-se a um documento escrito e assinado é que existe a “Assinatura Eletrônica” criptografada e protegida de tal forma que apenas o seu portador poderia assinar, sem o perigo de interferência de invasores. Somente assim presumir-se-ia verdadeiro o documento eletrônico, muito embora essa presunção seja iuris tantum ${ }^{13}$, segundo o disposto no art. 372 - CPC.

Para corroborar com a idéia da Força Probante dos Documentos Eletrônicos, devemos atentar para o disposto no art. 374 do mesmo diploma legal:

"O telegrama, o radiograma ou qualquer outro meio de transmissão tem a mesma força probatória do documento particular, se o original constante da estação expedidora foi assinado pelo remetente”.

${ }^{13}$ Uma presunção iuris tantum é aquela presunção que admite prova em contrário, ou seja, é relativa. Se a parte que poderia impugnar essa presunção perder o prazo, essa presunção torna-se iure et de iure, ou seja, uma presunção que seria praticamente uma certeza. 
Assim sendo, como o artigo usou a expressão "qualquer outro meio de transmissão”, pode ser que, fazendo uma interpretação extensiva à luz das novas relações contratuais, esteja incluído aí a Internet ou até documentos que sejam enviados via e-mail. Também se atentarmos para a parte final do artigo, onde ele condiciona, para que o documento transmitido tenha a mesma força probatória do original, que o original constante da estação expedidora tenha que ter sido assinado pelo remetente, iremos ver que, ao levarmos isso para a seara da informática, faz-se necessária, também a segurança da Assinatura Digital.

Muito embora o Código de Processo Civil albergar, mesmo que tacitamente, os Contratos Eletrônicos como prova, existe, como já foi dito, a grande barreira da Segurança tecnológica, para garantir, por meio de recursos de criptografia, o sigilo e a fidedignidade dos documentos eletrônicos.

A título de curiosidade, existe aqui no Brasil uma entidade privada, chamada Certsign, com sede no Rio de Janeiro, que é a única com legitimidade para Certificar documentos eletrônicos. Ela segue práticas já consolidadas pela legislação internacional, para proceder com a identificação de quem deseja que seu documento possua uma Assinatura Digital com criptografia própria. Ela faz isso mantendo um contrato de emissão de assinaturas digitais registrado em um Cartório de Títulos e Documentos.

\section{\ Princípios Contratuais aplicáveis aos Contratos Eletrônicos}

A Teoria Geral dos contratos elenca vários Princípios que irão servir de base para a interpretação e entendimento do Universo Contratual. E, nesse capítulo, vamos elencar os Princípios que seriam aplicáveis aos Contratos Eletrônicos.

Dentre esses Princípios, destacam-se o Princípio da Autonomia da Vontade, o da Força Obrigatória dos Contratos, e, por último, mas não menos importante, o da Boa-Fé Contratual.

O Princípio da Autonomia da Vontade é um princípio que já se tornou um clássico, inspirado no Código Francês, esse Princípio reza que a pessoa civilmente capaz possui liberdade de contratar. Essa liberdade de contratar permite que as partes escolham modelos contratuais previsto no ordenamento jurídico nacional (contratos Típicos), ou criem uma modalidade de contrato de acordo com as suas necessidades (contrato Atípico). 
Entretanto, essa liberdade de vontade contratual sempre sofreu limitações por parte de princípios ou normas de ordem pública, ou seja, o Estado está cada vez mais suprimindo essa liberdade. Se tomarmos como exemplo o art. 421 do Novo Código: “A liberdade de Contratar será exercida em razão e nos limites da função social do contrato”. Isso, de certa forma é melhor para os contratantes, com especialidade para os chamados hiposuficientes ${ }^{14}$, pois, ao limitar a liberdade de contratar para exercida somente dentro dos limites da função social do contrato, o Estado estaria coibindo cláusulas abusivas ou injusta para uma das partes. Esse Princípio aplica-se também aos Contratos Eletrônicos, visto que os mesmos também devem possuir uma função social, sob pena de serem coibidos pelo Estado, se não procurarem esse fim.

O Princípio da Força Obrigatória dos contratos, diz que o contrato faz lei entre as partes, ou seja, é uma confirmação do antigo Princípio do pacta sunt servanda ${ }^{15}$. Esse Princípio, além de ser uma das bases do Direito Contratual, existe para dar uma força maior, bem como uma validade e eficácia aos contratos.

Ele parte do pressuposto de que, se as partes contrataram de livre e espontânea vontade, e expressaram essa convergência de vontades em um documento público ou particular, é por que a situação atual foi por eles desejada.

Mas, como toda regra tem exceção, esse Princípio também não seria absoluto, visto que o ordenamento alberga também a chamada Teoria da Imprevisão dos Contratos (ou Cláusula “rebus sic stantibus”"16), que diz que, por conta de um fato futuro, imprevisível e extraordinário, o contrato ficar excessivamente oneroso para uma das partes, pode ser concedida a Revisão Judicial do mesmo, no intuito de ajustá-lo, para que o mesmo cumpra o fim social a que se destina. Também é aplicável aos Contratos Eletrônicos, haja vista que, até nestes pode haver um fato imprevisto que mude totalmente a reciprocidade eqüitativa de obrigações e direitos, com especialidade aos que forem formados no âmbito internacional, pois, geralmente, submetem o seu pagamento à variação cambial.

\footnotetext{
${ }^{14}$ Hiposuficiente é toda a pessoa que não tem muitos recursos financeiros, de modo que não possa, por si só, defender-se judicialmente, ficando, de certa forma, à mercê das vontades dos mais fortes, economicamente falando.

${ }^{15}$ Do latim: As partes se submetem ao pacto.

${ }^{16}$ Do latim: As coisas devem permanecer como estão.
} 
Finalmente, o Princípio da Boa-Fé Contratual, que é o princípio basilar que deve, em tese, reger toda e qualquer relação contratual, diz que as partes devem agir de forma correta (ou seja, de boa-fé) durante todo o contrato, desde a sua formação atéo adimplemento. Esse princípio mantém mais relação com a questão da interpretação dos contratos, devendo-se, quando for feita a interpretação, analisar-se a boa-fé dos contratantes, seu nível sociocultural, bem como o as circunstâncias em que contrataram.

Esse princípio, pelo fato de ser a base de todo contrato, também deve aplicarse aos Contratos Eletrônicos, pelo fato destes também serem manifestações de vontade, que não devem, portanto, estarem eivados de má-fé contratual.

\section{Conclusões}

A Internet, além de um excelente meio de comunicação, tornou-se uma rápida maneira de se constituir obrigações. Em virtude disso, os instrumentos contratuais sofreram diversas mudanças no decorrer do tempo, adaptandose constantemente à nova realidade social, e os Contratos Eletrônicos nada mais são do que apenas uma novas formas de se contratar que precisam se adequar ao sistema.

Apesar das suas inúmeras vantagens, entre elas, a rapidez e a facilidade, verifica-se que ainda existem barreiras tecnológicas e legislativas que impedem a disseminação dessa nova forma contratual. As barreiras tecnológicas residem, principalmente no tocante à segurança, pois o alto custo de sistemas de segurança capazes de deter a ação dos crackers (“invasores cibernéticos”), ainda é um problema. As barreiras legislativas dizem respeito à legitimação da força probante dos documentos eletrônicos e a regulamentação da sua forma.

Enquanto essa lacuna legislativa não é suprida, por meio de regulamentação específica para o comércio eletrônico, pode-se perfeitamente adaptar uma parte da atual lei civil para reger as Novas Relações Contratuais, quais sejam, os Contratos Eletrônicos, sempre, é claro, observando os Princípios clássicos do Direito Contratual.

No tocante à prova de um documento ou Contrato Eletrônico, a Lei Processual não faz nenhum objeção expressa à esse contratos, pois ela pode albergar vários tipos de prova, inclusive aquelas não previstas naquele diploma legal, 
no entanto, é necessário todo um aparato de segurança eletrônica (como as “Assinaturas Digitais”) para que estas provas eletrônicas tenham o mesmo efeito que provas documentais comuns.

Após a análise dos Contratos Eletrônicos à luz do Código de Defesa do Consumidor, pode-se ver que também não há nenhuma objeção, desde que, esses novos contratos, ao conter relações de consumo, não prejudiquem os consumidores. Em outras palavras, também nesses contratos aplicam-se as normas do CDC.

Finalmente, nota-se que os Contratos Eletrônicos no Direito Brasileiro ainda estão começando a manter novas relações e a produzir seus efeitos, e os operadores do direito ainda não se depararam com grandes discussões acerca do assunto, que, cedo ou tarde, chegarão. 


\section{Bibliografia}

MELLO, Leonel Itaussu A. e COSTA, Luis César Amad. História Moderna e Contemporânea. São Paulo: Scipione, 1996.

BARROS, Felipe Luiz Machado. "Dos Contratos Eletrônicos no Direito Brasileiro”. In www.jus.com.br. Acessado em 11/9/2004.

SILVA, Rosana Ribeiro da. "Contratos Eletrônicos". Disponível em: www.jus.com.br. Acesso em: 9/9/2004.

MENEZES, Glauco Cidrack do Vale. O Direito Processual e a Internet: A Instrumentalização de uma nova realidade jurídica, Coimbra - Portugal: Universidade de Coimbra, 2003 (Dissertação de Mestrado).

GONÇALVES, Sérgio Ricardo Marques. O Comércio Eletrônico e suas implicações jurídicas. In Direito Eletrônico, Coordenador: Renato Opice Blum. São Paulo: EDIPRO, 2001.

TAREDA, Michelle Toshiko. Contratos eletrônicos e suas implicações na ordem jurídica - A defesa do Consumidor. In, Novas fronteiras do Direito na Informática e Telemática, Coordenador: Luiz Olavo Baptista. São Paulo: Saraiva, 2001.

WIELEWICKI, Luis. Contratos e Internet - Contornos de uma breve Análise. In Comércio Eletrônico, Organizadores: Ronaldo Lemos da Silva Junior e Ivo Waisberg. São Paulo: RT, 2001.

BARRETTO, Ana Carolina Horta, Assinaturas Eletrônicas e Certificação, in O Direito e Internet, Coordenador: Valdir de Oliveira Rocha Filho. Rio de Janeiro: Forense Universitária, 2002.

VENOSA, Silvio de Salvo. Direito Civil: Parte Geral. São Paulo: Atlas, 2000.

VENOSA, Silvio de Salvo. Direito Civil: Teoria Geral das Obrigações e Teoria Geral dos Contratos. São Paulo: Atlas, 2000.

MATTE, Maurício. Internet - Comércio Eletrônico. São Paulo: LTr, 2001. JUNQUEIRA, Miriam. Contratos Eletrônicos. Rio de Janeiro: Mauad, 1997. Novo Código Civil. 10ª ed. Saraiva, 2004. 